\title{
Computador na Educação: artefato capaz de auxiliar na problematização das práticas de ensino e aprendizagem?
}

\author{
Ricardo Jullian da Silva Graça ${ }^{1}$, Flora Prata Machado ${ }^{1}$, Ana Cristina Moraes da \\ Costa $^{1,2}$
}
${ }^{1}$ LIpE - Escola Politécnica - Universidade Federal do Rio de Janeiro - RJ - Brasil
${ }^{2}$ Secretaria de Estado de Educação do Rio de Janeiro - SEEDUC-RJ
\{jullian@poli.ufrj.br,floramachado@hotmail.com, anacristina@poli.ufrj.br\}

\begin{abstract}
This paper discusses the possibility of problematization and modifications in the didactic practice of elementary school teachers through certain processes of appropriation of pedagogical use of Information and Communication Technologies (ICT). The empirical research, designed in a participative format, was conducted with a group of 13 teachers from 5 public schools in 2017. The Laboratory of Informatics for Education, at Federal University of Rio de Janeiro, conducted continuing professional development courses on pedagogical use of ICT for these teachers. We try to identify, through the course, who had succeeded to problematize and modify certain aspects of their practice of teaching.
\end{abstract}

Resumo. Este artigo discute a possibilidade de problematização e de modificações na prática didática de professores do Ensino Fundamental através de determinados processos de apropriação de uso pedagógico das Tecnologias da Informação e Comunicação (TICs). A pesquisa, desenvolvida de forma participativa, realizou-se com um grupo de 13 professores de 5 escolas públicas ao longo de 2017. O Laboratório de Informática para Educação, da Universidade Federal do Rio de Janeiro (LIpE/UFRJ), realizou um curso de formação continuada sobre uso pedagógico das TICs para esses professores. Buscamos identificar, ao longo do curso, quais deles haviam conseguido ou não problematizar e modificar certos aspectos de sua prática didática.

\section{Introdução}

Estudos apontam que a escola, em geral, comporta-se como uma instituição refratária a mudanças e com estruturas conservadoras e rígidas, predominando uma escolarização baseada no ensino tradicional ou bancário, como definido por Paulo Freire (1987). Na forma como se organizam nossos sistemas escolares, resta aos professores apenas tentar transmitir a seus alunos os chamados conteúdos escolares [Schön 1992], não cabendo a discussão sobre currículo, ou metodologia de aprendizagem e muito menos sobre os objetivos da educação.

Apesar disso, em diversos momentos, desde o início do século passado, diversas tecnologias (rádio, cinema, TV, vídeo cassete, etc.) trouxeram a promessa de transformar radicalmente a educação escolar [Karsenty 2010]. Entretanto, o que observamos foi que uma após outra, tais tecnologias foram ajustadas ou "domesticadas" a serviço de um ensino tradicional conteudista. 
VII Congresso Brasileiro de Informática na Educação (CBIE 2018)

Anais do XXIV Workshop de Informática na Escola (WIE 2018)

Um último exemplo, nas últimas décadas, tem sido a tentativa de utilizar o computador na educação, ou como classificam alguns autores, as chamadas Tecnologias da Informação e Comunicação (TICs). O escritor Gavriel Salomon, no seu artigo “Technology and Pedagogy: Why Don't We See the Promised Revolution?” (2002), analisando essa situação, apontou 3 razões gerais e interligadas para esse fracasso, que define como:

- “O Paradoxo Tecnológico” - A introdução das TICs na educação não alteraria o paradigma de ensino predominante, pautado na transmissão de conteúdos. Resultado da tendência geral do sistema educacional de preservar-se, como também de suas práticas através da assimilação das novas tecnologias em suas práticas instrucionais já existentes. A tecnologia torna-se “domesticada”, significando que somente é permitido fazer precisamente o que se encaixa na filosofia educacional vigente de "transmissão cultural" e de "treino para o mundo de ontem". De acordo com essa filosofia, o conhecimento deve ser transmitido de cima para baixo, daqueles que sabem para os que não sabem; existe um corpo de conhecimento importante que todos terão que dominar que se classifica também como "saber escolar" [Schön 1992].

- “O foco tecnocêntrico” - Tudo que você precisa é equipar as escolas com computadores e com acesso à Internet e pronto: a revolução vai começar! Consequentemente, nada será alterado, nada é renovado; computadores são introduzidos nas salas de aula e todo mundo espera o milagre tecnológico acontecer.

- "Pesquisas mal orientadas" - As pesquisas de avaliação sobre a utilização das novas mídias na educação geram o que Salomon denomina como "paradigma da corrida de cavalos" ao perguntar: o uso do meio X irá produzir melhores resultados de aprendizagem do que o meio Y? E assim, aplicamos os mesmos testes e métodos de avaliação de aprendizagem construídos dentro de um modelo conteudista em experiências centradas numa pedagogia geralmente orientada para a solução de problemas. Essa mesma medida de avaliação aplicada em situações completamente diferentes normalmente produz distorções.

\section{Mudar algo é possível?}

Apesar das dificuldades em promover mudanças na instituição escolar como um todo, desde sua própria inércia, além das dificuldades de uso das TICs de forma problematizadora, será que é possível fazer algo?

Entre os diferentes fatores apontados pelo pouco sucesso alcançado pelo uso das TICs na Educação, alguns citam a precária formação de professores nessa área, seja na modalidade inicial ou continuada. Algumas tentativas de formação existentes trazem soluções prontas para implementação pensadas por outros como manuais elaborados pelos chamados especialistas em informática educacional, em que o professor deverá apenas ser o executor. Outras formações são apenas teóricas, abandonando o professor muito antes que ele efetivamente entre com sua turma no laboratório de informática da escola.

De acordo com Paulo Freire em seu livro Pedagogia da Autonomia: Saberes Necessários a Prática Educativa (2011), ensinar exige pesquisa:

"Não há ensino sem pesquisa e pesquisa sem ensino.

Esses que-fazeres se encontram um no corpo do outro. 
VII Congresso Brasileiro de Informática na Educação (CBIE 2018)

Anais do XXIV Workshop de Informática na Escola (WIE 2018)

Enquanto ensino continuo buscando, reprocurando. Ensino porque busco, porque indaguei, porque indago e me indago. Pesquiso para constatar, constatando, intervenho, intervindo, educo e me educo. Pesquiso para conhecer o que ainda não conheço e comunicar ou anunciar a novidade.” (p.31)

Assim, o Laboratório de Informática para Educação (LIpE/UFRJ) ${ }^{1}$, através de seus cursos de formação continuada e da metodologia participativa [Thiollent 2000], estimula professores a que se tornem pesquisadores das possibilidades de uso das TICs em sua prática pedagógica. Esse nos parece ser um caminho viável não apenas para introduzir novas tecnologias na educação, mas principalmente para se repensar a própria prática educacional como um todo, principalmente se acrescentamos às TICs, as chamadas TACs - Tecnologias de Aprendizagem e Convivência [Severo 2016]:

"Tião Rocha cunhou esse termo fazendo uma associação com o som emitido pelos relógios de corda ou de pêndulo (tic-tac, tic-tac). Na época da formação da Fabriqueta de Softwares (empreendimento social protagonizado por jovens de Araçuaí/MG), além de muita técnica, os jovens aprendiam a trabalhar em grupo, a ser solidários uns com os outros, a conversar na roda para planejar o trabalho e também resolver suas diferenças.” (p. 14)

Através das TACs Tião Rocha se apropria do pensamento Freiriano pelas práticas de dialogicidade, problematização, respeito e valorização da história de vida de cada educador-educando como ator/autor de sua própria prática.

\section{O Curso de Extensão Tecnologia \& Educação}

O curso de formação continuada de professores Tecnologia \& Educação é organizado em três módulos. Em seu primeiro módulo, os professores são orientados a analisar diferentes possibilidades de uso da informática em suas disciplinas. Para facilitar a compreensão, realizamos atividades práticas em laboratório com esses professores para que possam explorar diferentes formas de utilização do computador na construção de seu próprio conhecimento. Finalizando o primeiro módulo, os professores se dividem em equipes para defender, num exercício tipo júri simulado, diferentes possibilidades de uso da informática na educação. Assim conseguem aprofundar a discussão sobre as possibilidades e os limites das diferentes abordagens existentes.

No segundo módulo os professores planejam, em duplas ${ }^{2}$, as atividades a serem realizadas no laboratório de informática da escola com seus alunos. Essas atividades devem se relacionar com as demais aprendizagens que estão sendo trabalhadas por eles em sala de aula. Cada atividade em laboratório pode ter a participação de mais de um professor e conta com o apoio de pelo menos um integrante do LIpE/UFRJ e após sua

1Desde 1994, o LIpE/UFRJ realiza sua ação extensionista a partir dos pressupostos teóricometodológicos da pesquisa participativa, baseada nos princípios de dialogicidade, interdisciplinaridade, ação emancipatória e indissociabilidade entre ensino, pesquisa e extensão. Desde sua criação atua na formação continuada de professores de escolas públicas para a utilização da Informática para a Educação, sempre com a participação de alunos de graduação da Universidade Federal do Rio de Janeiro.

2 No momento de inscrição no curso, solicitamos que cada escola convidasse pelo menos 2 professores. 
VII Congresso Brasileiro de Informática na Educação (CBIE 2018)

Anais do XXIV Workshop de Informática na Escola (WIE 2018)

execução é avaliada de forma individual e coletiva. Esses passos são repetidos em um processo de planejamento, execução e avaliação com pelo menos cinco dias de atividades práticas em laboratório de informática.

No módulo final os educadores são orientados a realizar, individual e coletivamente, reflexões sobre o trabalho realizado sob forma de relatórios e artigos acadêmicos.

Ao longo de todo o curso, textos acadêmicos sobre informática e educação são distribuídos e discutidos pelos participantes sob forma de reações ${ }^{3}$ que são compartilhadas com todo o grupo através de lista de e-mail e sempre que possível conversadas na roda presencial também. Ao longo do $2^{\circ}$ e $3^{\circ}$ módulos, algumas das análises e avaliações sobre as práticas realizadas pelos professores são compartilhadas também com todo o grupo.

\subsection{Escolas e professores integrantes do Curso Tecnologia \& Educação em 2017}

A partir das conversas iniciais com a Secretaria Municipal de Educação do Rio de Janeiro (SME/RJ), decidimos concentrar nossa atuação em cinco escolas municipais da $11^{\text {a }}$ Coordenadoria Regional de Educação (CRE), localizadas na Ilha do Governador. Nas reuniões com a Coordenadoria dessa região, optamos por convidar escolas que quisessem reativar seus laboratórios de informática e que pudessem encontrar pelo menos dois professores interessados em participar do curso.

Entre as escolas que aderiram ao projeto tivemos o seguinte perfil de professores inscritos:

- Escola A: Duas professoras que trabalham com as séries iniciais do Ensino. Fundamental 1 (E. F. 1- turmas do $1^{\circ}$ ao $5^{\circ}$ ano em que há um professor dedicado a cada turma).

- Escola B: Duas professoras nas séries finais do E. F. 1. Essa escola também indicou um terceiro professor de Ensino Fundamental. 2 (E. F. 2 - turmas do $6^{\circ}$ ao $9^{\circ}$ ano em que existe a divisão de professores por disciplinas) que não concluiu o curso. no E. F. 2.

- Escola C: Um professor de matemática e uma professora de história que atuam

- Escola D: Uma professora de matemática do E. F. 2. A outra professora inscrita não conseguiu participar por ser a diretora adjunta da escola.

- Escola E: Uma professora de educação especial (por suas condições específicas, essa escola não poderia liberar dois professores para o curso ao mesmo tempo).

Além dos professores indicados pelas escolas também tivemos a participação de quatro convidados externos:

- Uma professora integrante da SME/RJ; uma professora de educação especial de uma escola de referência na área; um graduando em informática que trabalha numa escola localizada em outro município do Rio de Janeiro (indicado por professora

3 Com pelo menos 24h de antecedência ao encontro presencial semanal, cada educador deve enviar para o grupo de e-mail suas impressões sobre o texto com aproximadamente 250 palavras. 
VII Congresso Brasileiro de Informática na Educação (CBIE 2018)

Anais do XXIV Workshop de Informática na Escola (WIE 2018)

participante do curso em 2016) e um integrante de nosso laboratório com licenciatura em História.

Importante observar que esses quatro participantes foram convidados a participar na formação das duplas de trabalho e a realizar suas práticas numa dessas escolas. Tentamos incluir também duas professoras que trabalham com educação de surdos que, por dificuldades pessoais, não conseguiram participar do curso.

\subsection{TICs e TACs no Curso}

Não foi objetivo do curso “Tecnologia \& Educação” promover a aprendizagem das TICs diretamente, mas antes facilitar que cada professor explorasse diferentes possibilidades do uso delas em suas aulas. Como observamos que existem diferentes níveis de conhecimento entre os professores, desde alguns que apresentavam dificuldades com uso básico, até outros que já possuíam conhecimentos de linguagens de programação, apresentamos possibilidades de uso das TICs na educação com diferentes níveis de complexidade.

Em relação às TACs que tínhamos como objetivo desenvolver com os professores ao longo do curso, devido a limitação de espaço do presente trabalho, vamos analisar o que conseguimos promover de aprendizagens em relação ao que classificamos como TACs 1 e 2:

TAC1- Aprender a trabalhar em dupla com outro educador;

TAC2- Aprender a "conversar na roda para planejar o trabalho e resolver as diferenças” (como afirma Tião Rocha);

Essas seriam as principais TACs, pois o que observamos ao longo de mais de 20 anos de atuação do LIpE/UFRJ nas escolas é que, via de regra, o trabalho do professor se dá de forma isolada. Os diversos espaços coletivos na instituição escolar normalmente servem apenas como possibilidade de catarse, onde os docentes reclamam da falta de preparo de suas turmas, de problemas de disciplina ou de questões burocráticas, materiais e administrativas. O centro da prática de ensino-aprendizagem normalmente não é tocado. Existindo um quase pacto de silêncio, onde cada um não deve falar de suas dúvidas ou inseguranças e muito menos sobre propostas de mudanças.

Infelizmente, quando algum professor tenta sair dessa espécie de pacto de silêncio, logo é rotulado de intrometido, excêntrico ou desadaptado. E assim resta a esse professor se adaptar ou assumir o papel de diferente e ser geralmente isolado do restante do grupo. Resumindo não há trabalho coletivo em relação à construção de práticas de ensino e aprendizagem nessas escolas. Se as TICs servirem a esse propósito, já teremos dado um importante passo na possibilidade de mudança.

Um primeiro estímulo para promover a aproximação é dado desde o primeiro dia do curso, em que os professores são orientados a trabalhar em duplas, preferencialmente os que irão atuar na mesma escola. A diferença de níveis de conhecimento prévio de uso da informática já serve de primeiro estímulo para o trabalho em equipe. Assim, um professor normalmente começará a passar um pouco do conhecimento que tem a mais de informática para o outro, desde o início das atividades. 
O passo seguinte consta do planejamento das atividades que deverão reunir o uso do computador com às aprendizagens esperadas pelos alunos. Nesse momento, observamos que, às vezes, os papéis se invertem entre os professores da dupla. Agora quem tem mais experiência em planejamento de atividades educacionais poderá ser o professor que possui menos experiência em informática.

\subsection{Analisando as TACs 1 e 2}

Dos dezesseis educadores que se inscreveram no curso, iremos considerar para análise apenas treze, pois três desistiram inicialmente, não comparecendo ou não chegando ao segundo encontro.

Dos treze participantes, conseguimos estabelecer cinco duplas de trabalho permanente ao longo de todo o curso. Entre os professores que trabalharam a maior parte do tempo de forma isolada, um desistiu um pouco antes dos últimos encontros.

Podemos considerar que a dupla que apresentou maior avanço em relação à TAC1 foi a dupla da escola B. Apesar de não possuírem prática anterior no uso das TICs em educação, possuíam conhecimento básico de informática e conseguiram planejar uma sequência de atividades comuns para suas turmas, fazendo pequenos ajustes de acordo com as necessidades. Além do bom planejamento, houve a colaboração direta de outra professora (responsável pela sala de leitura) em vários momentos no laboratório de informática. Após a avaliação conjunta das sequências didáticas, as professoras ainda conseguiram realizar, em parceria, atividades extraclasse relacionadas ao projeto que estava sendo desenvolvido na escola. Abaixo, destacamos trechos de relatos das professoras ao longo do curso que reforçam nossa avaliação:

"Contar com a professora do quinto ano e seus alunos no projeto também aumentou a proporção do trabalho e seus resultados positivos”. (professora $x$ ).

"As palavras-chave para qualquer trabalho diferenciado com os alunos é planejamento e trabalho em equipe, sem um planejamento prévio, essas atividades não poderiam ser feitas e sem o apoio de meus colegas de trabalho também não”. (professora $x$ ).

"Existe ainda a necessidade de contar com outros professores que venham a colaborar para que as aulas aconteçam e os projetos sejam desenvolvidos”. (professora y).

Três duplas apresentaram um bom desempenho em relação à TAC1. Podemos observar, no caso da dupla atuante na Escola A, que uma das professoras apresentou muita dificuldade no uso das TICs e assim boa parte do planejamento ficou sob responsabilidade de uma das professoras, produzindo certa dependência tanto no planejamento quanto na execução das atividades em laboratório. A dupla que trabalhou na Escola C apresentou desempenho satisfatório em sua parceria durante todo o curso. A dupla que atuou na Escola D, durante parte da prática dividiu suas atuações de forma que uma delas ficou responsável pelo ensino da parte técnica e a outra da matemática:

"Vale ressaltar que este trabalho foi realizado em parceria com [a amiga K] que entende muito da área 
VII Congresso Brasileiro de Informática na Educação (CBIE 2018)

Anais do XXIV Workshop de Informática na Escola (WIE 2018)

tecnológica e a parceria com ela foi essencial para o sucesso do projeto". (professora z).

Apenas uma dupla não conseguiu avançar na aprendizagem do trabalho em dupla, sendo que uma professora realizava o planejamento e a execução das atividades em turma, cabendo a outra principalmente a construção prévia das atividades no computador e a preparação do espaço do laboratório:

"Com a ajuda preciosa [de minha] colega de curso para as aulas práticas, foram previamente instalados nos computadores do Laboratório de Informática onde as práticas aconteceriam, os Programas necessários”. (professora w).

Tanto nessa última dupla quanto no caso específico de três professores que trabalharam a maior parte do tempo isoladamente, observamos certas dificuldades de relacionamento e comunicação que não fomos capazes de superar ao longo do curso.

Em relação à TAC2 acreditamos que não conseguimos atingir esse objetivo satisfatoriamente, tanto por dificuldades no próprio grupo quanto por falhas em nosso planejamento. Observamos que alguns professores tentaram monopolizar constantemente o tempo de fala na roda ampliada, enquanto outros apresentaram certa insegurança para se expressar. De nossa parte avaliamos que não dedicamos o tempo suficiente para o exercício da conversa em roda, pois sabemos que é necessário bastante tempo de exercício de diálogo para que certo nível de confiança comece a se consolidar.

\section{Considerações Finais}

Entre as cinco duplas, podemos considerar que uma apresentou excelente resposta em relação à TAC1, três apresentaram um bom avanço e uma não conseguiu estabelecer uma boa aprendizagem. Além disso, não conseguimos que três integrantes do curso sequer trabalhassem em duplas durante a maior parte do curso. Precisaremos buscar outras estratégias para enfrentar esse problema no futuro.

Observamos também que as duplas funcionaram melhor quando havia certo equilíbrio entre o nível de conhecimento das TICs e da parte pedagógica entre eles. Talvez seja necessário criarmos encontros extras sobre conhecimentos básicos de informática para alguns professores em paralelo ao curso. Notamos também que, em geral, as duplas conseguiram reproduzir essa forma de trabalho em dupla de parceria para seus alunos durante as atividades no laboratório de informática das escolas.

Quanto à TAC2, dedicamos pouco tempo para promover essa aprendizagem. Talvez por não valorizarmos devidamente os conhecimentos que são produzidos pelos próprios professores em sua prática cotidiana; priorizamos mais relatos de experiências de êxito de outros professores e especialistas externos ao grupo ao longo do curso.

Por fim, esperamos que as reflexões provenientes desse trabalho nos ajudem a aprimorar as próximas edições de nosso curso de extensão para professores, promovendo o maior equilíbrio possível entre as TICs e as TACs e assim estimulando mudanças mais profundas em suas práticas docentes.

\section{Referências}


VII Congresso Brasileiro de Informática na Educação (CBIE 2018)

Anais do XXIV Workshop de Informática na Escola (WIE 2018)

Freire, P. (1987) “Pedagogia do oprimido”, 17a . ed. Rio de Janeiro, Paz e Terra.

Freire, P. (2011) "Pedagogia da autonomia: Saberes Necessários a Prática Educativa”, $43^{\mathrm{a}}$. ed. São Paulo, Paz e Terra.

Karsenty, T. (2010). “As tecnologias da informação e da comunicação na pedagogia”. In A pedagogia: Teorias e práticas da antiguidade aos nossos dias. GAUTHIER, Clermont; TARDIF, Maurice (org.). Editora Vozes, Petrópolis, RJ pp. 328-350.

SALOMON, G. (2002) “Technology and Pedagogy: Why Don't We See the Promised Revolution?”, Educational Technology Magazine. v.42, n2, pp. 71-75, Março- Abril.

Schön, D. A. (1992) “Formar professores como profissionais reflexivos”. In: Nóvoa, Antônio. Os professores e sua formação”. Lisboa. Dom Quixote.

Severo, F. (2016) “TICs e TACs: O Refazimento de Softwares e Engenheiros no limiar entre as ciências e os segredos”. Dissertação de mestrado. Rio de Janeiro $\mathrm{UFRJ} / \mathrm{COPPE}$.

Thiollent, M. (2007) “Metodologia da Pesquisa-ação”. 15 ed., São Paulo: Editora Cortez.

Thiollent, M. (2000) "Metodologia Participativa e Extensão Universitária, Conceitos, Métodos e Práticas”. Niterói: EdUFF. 